\title{
Laboreal
}

Volume $14 \mathrm{~N}^{\circ} 1$ | 2018

O regresso ao emprego após um acidente de trabalho

\section{A abordagem ergológica para uma outra avaliação do trabalho social}

El enfoque ergológico para una otra evaluación del trabajo social

La démarche ergologique pour une autre évaluation du travail social

The ergology approach to reach a different assessment of the social work

\section{Ingrid Fouchecourt-Dromard}

Tradutor. Rui de Pinho e Nathalie Fernandes

\section{OpenEdition \\ Journals}

\section{Edição electrónica}

URL: http://journals.openedition.org/laboreal/534

DOI: $10.4000 /$ laboreal.534

ISSN: 1646-5237

\section{Editora}

Universidade do Porto

\section{Refêrencia eletrónica}

Ingrid Fouchecourt-Dromard, «A abordagem ergológica para uma outra avaliação do trabalho social ", Laboreal [Online], Volume $14 \mathrm{~N}^{0} 1$ | 2018, posto online no dia 01 julho 2018, consultado o 25 setembro 2020. URL : http://journals.openedition.org/laboreal/534 ; DOI : https://doi.org/10.4000/ laboreal.534

Este documento foi criado de forma automática no dia 25 setembro 2020.

\section{(c) (†) \&}

Laboreal está licenciado com uma Licença Creative Commons - Atribuição-NãoComercial 4.0 Internacional. 


\title{
A abordagem ergológica para uma outra avaliação do trabalho social
}

\author{
El enfoque ergológico para una otra evaluación del trabajo social \\ La démarche ergologique pour une autre évaluation du travail social \\ The ergology approach to reach a different assessment of the social work \\ Ingrid Fouchecourt-Dromard \\ Tradução : Rui de Pinho e Nathalie Fernandes
}

\section{REFERÊNCIA}

Fouchecourt-Dromard, I. (2017). Les Groupes de Rencontres du Travail pour une autre évaluation du travail social. A partir d'une expérience réalisée à la Caisse d'Allocations Familiales des Bouches du Rhône. Thèse de doctorat en philosophie. Aix Marseille Université. France.

\section{NOTA DO EDITOR}

http://dx.doi.org/10.15667/laborealxiv0118id

Manuscrito recebido em: janeiro/2018

Aceite após peritagem: maio/2018

Júri de tese: Presidente: Yves Schwartz; Orientador: Renato Di Ruzza; Arguentes: Ewa Bogalska-Martin, Louis Durrive; Examinador: Jean Luc Prades

1 A análise que se apresenta [1] corresponde a uma mobilização possível da abordagem da ergologia em resposta a um pedido institucional [2] sobre o tema da avaliação qualitativa do trabalho social. Para introduzir este artigo e precisar a nossa problemática, procederemos em primeiro lugar, a um trabalho de definição. 
2 É possível entender o trabalho social relacionando-o com as diferenças que o opõem à assistência e à caridade, cuja missão comum é de aliviar e socorrer o indivíduo. A ajuda apela ao imediatismo. Frequentemente, é necessária uma ajuda pecuniária ou hospitaleira que atende a uma necessidade vital, conforme a sua urgência. $O$ trabalho social vai mais longe, porque aqui socorrer simplesmente é insuficiente. Para além da satisfação imediata, a pessoa a ajudar, vulnerabilizada há já algum tempo, deve poder reconquistar a sua capacidade de responder, no mínimo, às exigências do seu ambiente. Ao contrário da assistência e da caridade, o trabalho social, como qualquer outra atividade de cuidado (Worms, 2012), visa não somente socorrer no imediato, mas também prolongar este socorro por meio de um apoio, de um acompanhamento. Em última análise, o trabalho social resulta do entrelaçamento de três contribuições: a do Estado, que coloca à disposição recursos, dispositivos de socorro; a do trabalhador social, que se implica pessoalmente na resposta a um pedido singular, que se mobiliza a criar com o outro uma relação de confiança para o acompanhar - ir onde ele vai, juntando esforços; e, finalmente, a da pessoa que solicita ajuda, que se compromete com o que emerge de si, das suas capacidades, das suas experiências e das suas habilidades.

3 A avaliação é um instrumento de medida, um novo modelo de exercício de poder que surge desde o final da década de 1970, e consiste em governar pelo resultado, pela medida de execução de objetivos quantificados, recorrendo a indicadores de desempenho (Ogien in Bocquet, 2016). Esta modalidade é característica da sociedade moderna, que a tornou uma técnica de gestão. Quando se trata de avaliar um trabalho dirigido a seres humanos, múltiplos valores coexistem, formando, assim, dois 'mundos de valores' (Schwartz \& Durrive, 2009a): o dos valores dimensionados, configurado por números, quantidades que para muitos circulam no mundo mercantil; e o dos valores não dimensionados que emanam do político, do 'bem comum' (a saúde, a educação, os serviços sociais). Para estes últimos, não existe nem limites nem hierarquia entre eles. Se esses dois mundos coabitam e se misturam no espaço social, a formulação 'avaliação do trabalho social' tende a fazer esquecer as suas possíveis contradições.

O trabalho social não escapa à regra do número e, paralelamente, do seu valor político, cabe-lhe então ser mensurável e rentável. Mas o que se deve avaliar no trabalho social: a sua utilidade social ou os seus custos de produção? O meio ou a finalidade? As avaliações em curso a propósito do trabalho social dividem-no, medem-no, traduzemno em dados quantificados. Elas centram-se mais no dimensionamento (tempo de trabalho e produtividade) ou na satisfação daqueles que beneficiam do trabalho social. Nunca têm em conta os sentimentos daqueles que acompanham. Se os saberes digitais obtidos pelas avaliações clássicas mostram uma certa imagem dos trabalhadores sociais, que lugar se atribui aos saberes qualitativos, àqueles que resultam da qualidade, portanto, das maneiras de fazer, dos saberes que só podem ser narrados, porque pertencem apenas a si mesmos? Se o socorro é o único avaliado, o julgamento de valor não é distorcido?

Uma primeira hipótese é então avançada: não podemos apenas avaliar o trabalho social usando um único modelo avaliativo, um modelo quantitativo, porque o projeto político realizado pelo trabalho social não pode ser traduzido em números. Torna-se necessário levar em conta o significado do propósito da ação e as condições de sua eficácia.

De acordo com o comando institucional, o novo modelo avaliativo não pretendia substituir os outros, mas complementá-los, oferecendo aos decisores uma leitura 
adicional. De facto, a exclusividade dos pontos de vista obtidos faz com que a sua conjugação seja obrigatoriamente necessária a fim de fornecer uma explicação exaustiva da implantação do trabalho social institucionalizado. A complementaridade é de fundamental importância, pois sugere comensurabilidade. Ou seja, permite que as diferentes entidades avaliativas sejam consideradas de forma igualitária, permitindo a sua comparação, o seu confronto e a produção de novos conhecimentos. A complementaridade convida ao diálogo, à instrução mútua; exige o compromisso dialético, encoraja a 'espiral permanente de retrabalho do conhecimento' (Schwartz \& Durrive, 2009b, p. 264). De onde, a nossa segunda hipótese: ao dar visibilidade aos saberes resultantes do trabalho real, a avaliação produzida pode permitir a transformação das atividades do trabalho.

7 Devemos então refletir sobre a conceção de uma avaliação original pelo facto de que ela é baseada no conhecimento daqueles que trabalham. Assim, precisávamos prever uma maneira de recolher estes saberes e também tínhamos que considerar como estes 'saberes narrativos' (Gori, 2015) se tornaria comensurável com o conhecimento já produzido, conhecimento teórico, digital, resultante, nomeadamente, de outras formas de avaliação.

8 Em primeiro lugar, apresentaremos as principais etapas da avaliação qualitativa que propusemos e, em seguida, tentaremos mostrar como essa avaliação pode ser uma ferramenta interessante para uma modalidade de gestão original, especialmente em instituições públicas.

\section{As grandes etapas da avaliação ergológica}

Para realizar essa avaliação, contamos com a abordagem ergológica, uma abordagem que surgiu em França, no início dos anos, 80 sob a instigação de Yves Schwartz, filósofo e investigador da Universidade de Aix-Marseille. No coração dessa abordagem está o conceito de atividade, entendido aqui como um uso de si mesmo (Schwartz, 2000). Fazer uso de si mesmo é tratar subjetivamente os eventos que lhe são apresentados. É fazer uso do próprio ser físico, biológico, psíquico e social. A atividade é singular, é uma negociação em si, um debate personalizado pela história da nossa vida (Schwartz, 2000). Como tal, é a matriz de saberes originais, inéditos.

10 O desvio entre o trabalho prescrito e o trabalho real surge do encontro entre prescrições e uma personalidade singular. Este desvio resulta da atividade do trabalhador, do debate permanente que existe nele entre o que ele exige de si mesmo e o que os outros lhe pedem: a hierarquia, os colegas, os destinatários do trabalho, etc. Este desvio acorda, portanto, a todas as atividades da atividade humana a sua imprevisibilidade, a sua imponderabilidade, a sua variabilidade e, por conseguinte, a precariedade daquilo que as define. Somente a pessoa em questão pode atestar as razões e as escolhas na origem deste desvio. É, por esta razão, que nada de sério pode ser dito sobre o trabalho independentemente daqueles que trabalham. São, portanto, os seus sentimentos e as suas explicações que constituem o ponto de vista que se procura recolher e valorizar pela abordagem ergológica [3]. Esta baseia-se num princípio epistemológico de produção de conhecimento e num princípio ético, porque enfatiza a importância do julgamento pessoal.

11 Para realizar a avaliação qualitativa, ergológica, afastamo-nos necessariamente das avaliações clássicas. Por exemplo, a definição dos indicadores parecia-nos pertencer aos 
atores do trabalho e não ao avaliador. Foram os trabalhadores que tiveram que indicar o que deveria ser valorizado para eles no desempenho do seu trabalho. Circunstância também acentuada pelo facto de a abordagem a que nos referimos rever, em si, os modos operatórios classicamente admitidos nas ciências humanas e sociais (não se trata de fazer teoria sobre os factos ou confirmar hipóteses por meio de experiências empíricas; trata-se sobretudo de acompanhar o confronto, num plano igualitário, dos saberes digitais e dos saberes resultantes da experiência, para que cada um se possa impregnar do outro).

12 Uma vez que consideramos que aquele que faz é mais capaz de avaliar, é da nossa responsabilidade promover o surgimento do conhecimento gerado pela atividade e identificar nas trocas, os valores a partir dos quais cada um gere o desvio entre o que se prescreve e o real, para identificar recorrências na sua abordagem ao trabalho, ou seja, atualizar o que cada um faz para ser eficaz, e em nome do que faz, individual e coletivamente. Dito isto, este trabalho avaliativo não consistiu na realização de um catálogo de saberes-fazer singulares. Não é só o que diz respeito a si exclusivamente a nós mesmos que teremos que apontar, mas antes aquilo que encontra eco no coletivo. Tão pouco precisamos de apresentar as diferentes formas de abordagens colaborativas informais, mas deveríamos sobretudo tentar compreender o que favorece o seu desenvolvimento ou, pelo contrário, o que o inibe para permitir a cada um reconsiderar as suas maneiras de fazer, tendo em vista novos saberes que se lhe apresenta.

Como as diversas formas de avaliação presentes na instituição deveriam ser consideradas complementarmente, os saberes narrativos deveriam atingir o mesmo nível de grandeza científica que os saberes digitais. Isso significa que os saberes da experiência deveriam entrar em epistemicidade (em conceitos). A entrada em epistemicidade implica o controlo da sistematicidade. Como resultado, o acesso ao trabalho real é concebível a partir dos conhecimentos produzidos singularmente nas suas convergências coletivas (sistematicidade). Os pontos de concordância sobre o sentido dado ao trabalho permitem a transição para a abstração necessária ao trabalho de concetualização.

14 A entrada em epistemicidade foi possível por meio de um dispositivo original proposto pela abordagem ergológica que são os 'Groupes de Rencontres du Travail' ('Grupos de Encontros do Trabalho') (GRT), grupos de análise de experiência (Durrive, 2015), onde os profissionais são convidados a refletir e discutir o seu trabalho.

15 Nos GRT, a produção de saberes é baseada na dinâmica entre, por um lado, o polo dos saberes teóricos (produção antecipada de conhecimentos sobre a atividade de trabalho: formações, prescrições, regras, descritivos de funções, etc.); e, por outro lado, o polo dos saberes da atividade, da realidade dos trabalhadores. A dinâmica entre estes dois polos implica um enriquecimento mútuo desde que seja mantido num diálogo que aceite a comensurabilidade dos saberes [4]. Isso significa que os saberes em dialética entre estes dois polos são considerados da mesma grandeza, permitindo o seu confronto.

16 Escolhemos considerar a efetividade do trabalho social como um 'problema comum' que se articula entre atividade (uso de si), organização e política. Com referência a certos aspetos metodológicos da sociopsicanálise institucional [5], a implementação de um diálogo igualitário em três dimensões foi assim imaginado: entre pares (quatro ofícios foram solicitados), entre colegas e colegas de equipa (esses quatro ofícios 
formam a equipa de intervenções em trabalho social) e entre operadores e concetores (gestores).

17 A avaliação proposta foi então construída em três etapas: acompanhar a enunciação dos conhecimentos pessoais, apoiar a construção de pontos de vista partilhados e, finalmente, estabelecer comensurabilidade entre as avaliações. Ela torna-se uma avaliação feita de duas avaliações baseadas nas seguintes questões: qual é o meu trabalho? Como fazemos o trabalho social juntos? Os GRT foram usados para construir estas duas avaliações. Eles desenrolaram-se em nove sessões de três horas, uma vez por mês durante quinze meses. Os GRT são compostos por três fases: apreender a atividade; construir entre pares um ponto de vista coletivo sobre o trabalho; apreender o trabalho coletivo, o trabalho em equipa.

18 A primeira fase dos GRT é o feedback do conhecimento e a partilha de experiências pessoais entre pares. Outras técnicas qualitativas de recolha de informações foram mobilizadas: observação e entrevista livre. O esforço de adesão às situações era, portanto, necessário, a princípio, para desalojar evidências e aprofundar as aparências. Cada sessão deu lugar a uma síntese dos diversos elementos de conhecimentos recolhidos. Esta síntese foi distribuída aos participantes antes do encontro seguinte para ser submetida à sua validação. Foi também um novo meio para os profissionais confrontarem, mais uma vez, os seus conhecimentos, que foram enunciados no mês anterior.

19 A segunda fase dos GRT visa a construção, sempre entre pares, um ponto de vista partilhado sobre o ofício com base nas realidades de cada um. Admite-se, assim, o aumento em objetividade para construir um primeiro mundo comum, o do mundo profissional. Aqui os protagonistas, sempre reunidos em grupos de ofícios, tentaram colocar por palavras de forma argumentada (sem necessariamente encontrar consenso) o ponto de vista sobre o seu trabalho em relação aos constrangimentos que eles enfrentam. Isso permitiu a estes trabalhadores pares retrabalhar as suas profissionalidades e ampliar a sua visão dos meios empregues face à organização formal. Essas duas primeiras fases dos GRT permitem a formalização de uma primeira narrativa avaliativa, a do trabalho supostamente realizado por esses trabalhadores pares.

20 A terceira fase, a terceira intenção, visa, por sua vez, a transição de uma abordagem específica para uma abordagem global para entender o trabalho em equipa, um mundo comum mais amplo. Se até aí era uma questão de produzir conhecimento, desta vez queríamos entender o 'fabrico' do trabalho social de forma alargada, através da comunicação indireta. Os quatro grupos então, por nosso intermédio, comunicaram entre eles, trocaram perguntas e respostas. Havia uma hierarquia estatutária entre os participantes, entre os grupos. Como queríamos abordar o trabalho da 'equipa de intervenção em trabalho social', essa hierarquia organizacional obrigou-nos a encontrar soluções que permitissem materialmente a comunicação entre os grupos sem prejudicar a expressão. A ideia de colocar em cena vários grupos de ofícios diferentes foi inspirada pela sociopsicanálise. Jean Luc Prades explica, a esse respeito, que a multiplicidade de grupos, quando se reúnem, recompõe a instituição permitindo a cada um ir além da primeira identidade para a compreensão de todo o ato da instituição (Prades, 2007). Esta última fase permitiu o desenvolvimento de outra narrativa avaliativa, a do trabalho percebido pelos outros. 
21 A experiência que se acumula (Oddone, Re \& Briante, 1981) no seio de grupos homogéneos primeiro, e em grupos a seguir, permitiu-nos obter novas informações sobre o trabalho. Essa modalidade de produção de saberes combinou a expressão e a validação iniciando uma progressão entre subjetividade e objetividade, entre pares e entre membros de uma mesma equipa. A validação das crónicas da atividade, resultantes das observações da situação de trabalho, das sínteses de sessão, das questões e das respostas formuladas por cada um dos grupos foram as etapas necessárias para a construção de um julgamento de cientificidade que conferiu aos trabalhadores um estatuto particular: o de perito do seu trabalho. Esses peritos enunciaram saberes esperando o reconhecimento concetual, saberes que não pertencem a nenhuma disciplina porque advêm da experiência. A validação por vários permitiu a sua concetualização.

22 A partir dessas duas narrativas, construímos a avaliação final. Analisamos, registamos e transmitimos para a Gestão os saberes obtidos a partir do trabalho real. Este trabalho coletivo dá a ver um ponto de vista qualitativo do que produz a organização do trabalho, um ponto de vista científico, que se torna ele mesmo comensurável com outros pontos de vista.

\section{Avaliação ergológica ao serviço do 'ergogerenciamento'}

Propomos agora examinar o interesse da avaliação ergológica para as instituições públicas.

O nosso trabalho tende a mostrar que a avaliação ergológica tem sido benéfica para os trabalhadores mobilizados em GRT, porque eles reapropriam-se de uma espécie de legitimidade para falar sobre o seu trabalho e a sua organização. Eles pretendiam e solicitaram uma versão escrita da sua avaliação para mostrar os seus saberes-fazer e justificar as suas tomadas de posição face à organização prescrita. A avaliação ergológica irá, assim, permitir dar visibilidade a um outro tipo de valor naturalmente presente na empresa, o valor investido por cada um no processo produtivo. E sabemos que os trabalhadores precisam de ser valorizados e reconhecidos no e pelo que fazem, sobretudo porque estão frequentemente na melhor posição para propor pistas de melhoria (Hirigoyen, 2017). No entanto, a constatação da apropriação dos saberes da experiência pelos gestores mostrou-se mais difícil de estabelecer, isto porque esses líderes acabaram por se opor com desconfiança face ao nosso dispositivo. Estas reticências interpelam, porque supõem reservas sobre o valor e a utilidade dos saberes emergentes e isto vai ao encontro da pesquisa sobre a eficácia no trabalho e, especialmente, aqui, a eficácia do trabalho realizado para cumprir uma missão de serviço público.

Uma vez que visa alcançar o mesmo nível de cientificidade pelo conhecimento produzido tanto pelas avaliações qualitativas como pelas quantitativas; por aspirar a que a cientificidade de novos saberes seja possível pelo facto de que os trabalhadores concebem e conscientizam individualmente, coletivamente, e socialmente a sua atividade de trabalho. A avaliação ergológica participa no estabelecimento que cada ponto de vista tem a sua importância para a organização do trabalho. Para além da ambição apenas informativa da avaliação clássica, a avaliação ergológica é assim 
também uma ferramenta democrática, na condição, claro, de conceber que o diálogo está no fundamento da democracia e que a democracia parte do Homem [6], da sua atividade. Mais do que uma ferramenta de gestão, uma ferramenta para os gestores, a avaliação ergológica é assim uma ferramenta para todos os trabalhadores, independentemente do seu lugar no organigrama.

Quando a produção de saberes resultantes do trabalho é permitida na empresa, admitida a complementaridade de pontos de vista, a avaliação ergológica também endossa suplementarmente um papel político. O nosso trabalho permite ver, em particular, as consequências de uma abordagem excessivamente agressiva da lógica mercantil na organização das atividades que estão no centro de um projeto político (no sentido de politeia) como é o trabalho social, mas como é também a saúde ou mesmo o ensino. A lógica de mercado transforma os ofícios, fragiliza as identidades profissionais, fragiliza os corpos, desmantela os coletivos e neutraliza as relações e as interações. Elas mudam o sentido do trabalho, questionam o seu propósito e semeiam dúvidas sobre as expectativas de todos e em todos os níveis do organigrama. A avaliação ergológica coloca o problema do viver em conjunto como um problema comum e reconhece a necessidade de abordar em várias vozes as questões, nunca fáceis, do que é ser e trabalhar ao serviço do público, trabalhar em conjunto para produzir a riqueza essencial, para construir e melhorar o mundo comum no qual evoluímos combatendo desigualdades e injustiças. Mais do que uma despesa, essas atividades de serviço público são investimentos societais. É por essa razão que se torna obrigatório que seja debatido coletivamente a articulação entre o político, o mercado, a organização e o profissional, sabendo que cada um desses eixos responde a objetivos particulares e é atravessado por temporalidades específicas. Essas atividades exigem que o valor suplementar gerado pela implicação individual no trabalho em geral seja considerado e reconhecido, porque sem essa implicação individual, elas não persistiriam.

Se a avaliação é um risco porque pode revelar possíveis desvios entre o que se pensa fazer e o que é realmente feito, a avaliação ergológica supõe outros. Revoga os princípios classicamente estabelecidos da organização do trabalho. Não há mais, de um lado aqueles que sabem, e do outro aqueles que não sabem, aqueles que sabem sabendo por aqueles que não sabem (Schwartz, 2012). A instrução mútua admite uma circularidade de saberes contrária a uma conceção de cima para baixo. Permite regenerar as diretivas, rever as lógicas a partir do trabalho real, o trabalho realmente realizado. Oferece a possibilidade de gerir o mais próximo possível das realidades do trabalho e dos seus destinatários. A avaliação ergológica é, portanto, em última análise, um apoio para quem gostaria de ser ergo-gestor [7]. 0 ergo-gerenciamento é um projeto de uma nova gestão que quer ser mais democrática e, portanto, menos traumática. Uma gestão que não se estabelece sobre um saber hegemónico, autocrático, que não admite a pré-qualificação do poder sobre os saberes, que não nega o real do trabalho. Uma gestão do trabalho pelo trabalho, que dá lugar ao debate, à confiança, que também implica cada um na finalidade do trabalho.

28 Seria possível concluir postulando a ideia de que o ergo-gestor é aquele que aceita, permitindo que a complementaridade surja nas avaliações que ele gere, um retorno de experiência sobre as suas concetualizações organizacionais e de gestão. É o líder que reconhece que a sua atividade faz parte de um conjunto de atividades combinadas que ele precisa de conhecer e de entender. É um gestor que corre o risco de fazer de outra forma. De facto, se hoje as técnicas de gestão se focalizam mais do que no passado sobre 
a pessoa que trabalha, hoje, como no passado, o sofrimento no trabalho, o poder e o controlo pontuam o quotidiano dos trabalhadores e das trabalhadoras. 0 ergogerenciamento distingue-se então desta perspetiva indubitavelmente.

\section{BIBLIOGRAFIA}

Bocquet, B. (2016). La fièvre de l'évaluation. Quels symptômes?

Quels Traitements? Villeneuve d'Ascq: Presses Universitaires du Septentrion.

Di Ruzza R \& Halevi J. (2003). De l'économie politique à l'ergologie. Lettre aux amis. Paris: Editions L'Harmattan.

Durrive L. (2015). L'expérience de normes. Comprendre l'activité humaine avec la démarche ergologique. Toulouse: Editions Octarès.

Gori, R. (2015). La fabrique des imposteurs. Lonrai. Actes sud Editions.

Hirigoyen M.F. (2017). Le harcèlement moral au travail. Paris: Presses Universitaires de France.

Janover L. \& Rubel M. (2003). Karl Marx, Philosophie. Saint Amand: Galimard.

Mendel G. \& Prades J.L. (2002). Les méthodes de l'intervention psychosociologique. Paris: Editions La Découverte.

Oddone I., Re, A., \& Briante G. (1981). Redécouvrir l'expérience ouvrière. Paris: Editions sociales.

Prades J.L et les membres de l'ADRAP. (2007). Intervention participative et travail social. Un dispositif institutionnel pour le changement. Paris: L'Harmattan.

Schwartz Y. (2000). Le paradigme ergologique ou un métier de philosophe. Toulouse: Editions Octarès.

Schwartz Y. \& Durrive L. (2009a). Travail et ergologie: entretiens sur l'activité humaine. Toulouse: Editions Octarès.

Schwartz Y. \& Durrive L. (2009b). L'activité en dialogues: entretiens sur l'activité humaine. Toulouse: Editions Octarès.

Schwartz Y. (2012). Expérience et connaissance du travail. Millau: Les éditions sociales.

Worms F. (2012). Soin et politique. Paris: Presses Universitaires de France.

\section{NOTAS}

1. Este artigo retoma de forma sintética alguns elementos apresentados no trabalho de tese, para a obtenção de doutoramento em filosofia.

2. A pesquisa foi realizada em França no quadro de uma Convention Industrielle de Formation à la Recherche en Enterprise (Convenção Industrial de Formação para a Investigação em Empresa) (CIFRE) no quadro da instituição Caisse d'Allocation Familielle (CAF). O objetivo da CIFRE é cofinanciar a formação de um doutorando recrutado por uma estrutura estabelecida no território 
francês pertencente ao mundo socioeconómico, que o contrata para lhe confiar uma missão de investigação inscrevendo-se na estratégia de pesquisa e desenvolvimento, que servirá de suporte para a preparação da sua tese.

3. 'O que é, em certo sentido, mais rico do que a análise do trabalho por si só; porque está interessado em todos os 'usos de si', transcendendo todos os limites sociais, temporais e institucionais; apto a pensar as circulações e reinvestimentos entre eles. A análise do trabalho assalariado aparece deste ponto de vista mais pobre, na medida em que apenas determinados segmentos da vida humana são tidos em conta e onde a heterodeterminação das normas (variável segundo as épocas, as formas de gestão do trabalho) restringe a esfera das conquistas inventivas' (Schwartz, 2000, p. 422, tradução livre).

4. 'Os saberes académicos e os saberes não académicos são tendencialmente comensuráveis. E o diálogo que se deve instaurar entre eles é, desde logo, um 'diálogo igualitário' (talvez este seja o significado que deve ser dado ao 'diálogo socrático num duplo sentido')' (Di Ruzza \& Halevi, 2003, p. 68, tradução livre).

5. Desenvolvido por Gérard Mendel, 'a sociopsicanálise tenta compreender como o facto social influencia o facto psíquico individual, incluindo-se o inconsciente. Prática coletiva, procura estudar como os atores, organizados em grupos específicos (grupos homogéneos de ofício) e no quadro da sua atividade quotidiana, refletem por si mesmos sobre as forças que influenciam a sua personalidade'. (Mendel \& Prades, 2002, p. 53, tradução livre).

6. Enquanto 'Hegel parte do Estado e faz do homem o Estado transformado em sujeito, a democracia parte do homem e faz do Estado o homem transformado em objeto', ela é 'o homem socializado' (Marx cit in Janover \& Rubel, 2003, introdução, tradução livre).

7. 'Ergo-gestor significa que nós paramos, a todos os níveis das organizações humanas, de reificar as normas antecedentes, de reificar os parceiros, interlocutores, executores, usuários..., como se eles não fossem, dia após dia, confrontados com dramáticas de uso de si mesmos, portadores em níveis muito diversos de reservas de alternativas. Isto implica um desafio, uma vigilância, uma inquietude permanente por aqueles que têm essa responsabilidade ou esse poder, na sua relação com aqueles de quem esperam um resultado industrioso' (Schwartz \& Durrive, 2009a, p. 242, tradução livre). Essa postura é pertinente para todos os níveis hierárquicos.

\section{AUTORES}

\section{INGRID FOUCHECOURT-DROMARD}

Aix Marseille Univ, CNRS, Centre Gilles Gaston Granger (UMR 7304), Aix-en-Provence, France ingdrom@hotmail.fr 